\title{
Heterogeneity of technological regimes and banking efficiency in former socialist economies
}

\author{
Tigran Poghosyan $\cdot$ Subal C. Kumbhakar
}

Published online: 10 October 2009

(c) The Author(s) 2009. This article is published with open access at Springerlink.com

\begin{abstract}
Cost efficiency of banks in 20 former socialist emerging economies is analyzed using a latent class stochastic efficiency frontier model that explicitly accounts for unobserved differences in technological regimes due to the heterogeneity of economic environments in which the banks are operating. We find that banking systems in former socialist emerging economies are characterized by three distinct technological regimes. Based on the estimated efficiency scores we group the countries into three categories and provide an intuitive interpretation of these three regimes.
\end{abstract}

Keywords Banks - Cost efficiency ·

Latent class stochastic frontier model

JEL Classification C81 $\cdot$ D24

\section{Introduction}

Given the key role of banks as financial intermediaries in the process of transformation from a planned to a market economy, empirical assessment of efficiency of banking

This paper is part of Tigran Poghosyan's doctoral thesis at the University of Groningen. We thank Jakob de Haan, Elmer Sterken, Michael Koetter, Robert Lensink, Philip Molyneux, and Steven Ongena for valuable comments on the earlier draft of the paper. The opinions expressed in this paper are those of the authors and do not represent the official position of the International Monetary Fund.

T. Poghosyan $(\square)$

International Monetary Fund, 700 19th Street. N.W.,

Washington, DC 20431, USA

e-mail: tpoghosyan@imf.org; t.poghosyan@rug.nl

S. C. Kumbhakar

State University of New York, Binghamton, NY 13902, USA institutions in former socialist economies (FSE) has been given considerable attention in the recent empirical literature. Table 1 provides a brief overview of these studies, which share several common features. First, all of them are based on the frontier methodology according to which each bank's performance is benchmarked against a frontier reflecting the characteristics of the best-performing banks in the sample. ${ }^{1}$ Most of the studies employ stochastic frontier model (SFM), a parametric method that is less sensitive to the measurement errors in the sample compared to the alternative non-parametric method, viz., the data envelopment analysis (DEA). Next, efficiency analysis is conducted for two important measures of bank performance: costs and profits. In both cases, the variables determining technology of banks include quantities of outputs (such as loans, investments, other earning assets) and input prices (such as cost of capital, labor, financial funds). ${ }^{2}$ Finally, all studies assume that banks share a common production technology. In other words, production capacity of all banks is described by an identical production possibility frontier.

The aim of this paper is to relax the latter restrictive assumption by allowing for multiple technology regimes, conditional on differences in economic environments in which banks operate. The main criticism of the homogenous technological regime assumption adopted by all studies reviewed in Table 1 is the potential bias in the frontier estimates and, thus, the obtained efficiency scores (Orea and Kumbhakar 2004). Specifically, if the true technology is heterogenous, then the omitted technological

\footnotetext{
${ }^{1}$ Coelli et al. (2005) contains a textbook exposition of the frontier methodology. Berger and Mester (1997) and Hughes and Mester (2008) review applications of these methods in the banking industry.

${ }^{2}$ In most studies, the theoretical foundation for the choice of frontier determinants is either the intermediation approach (Sealey and Lindley 1977) or the modified production approach (Berger and Humphrey 1991).
} 


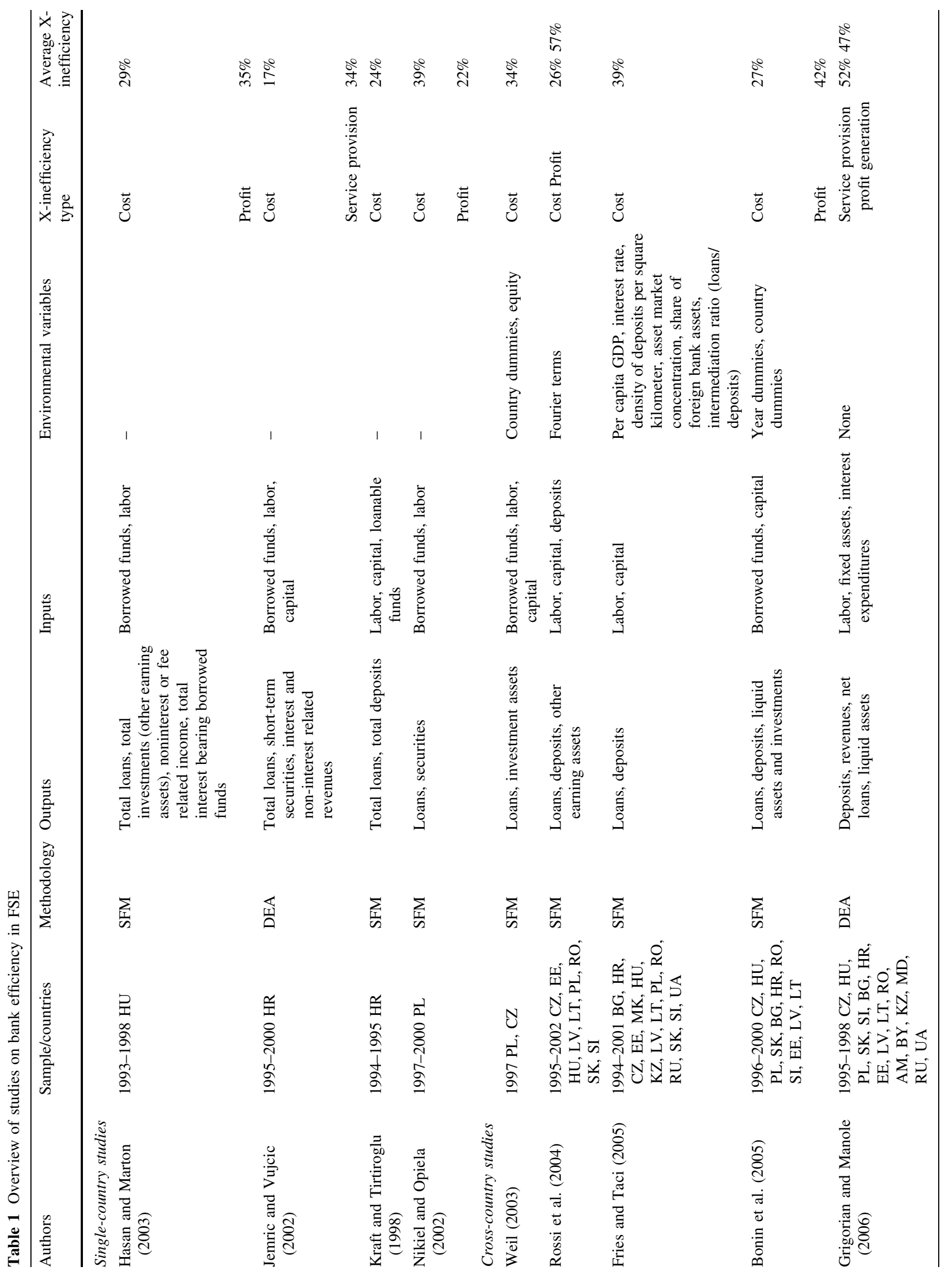




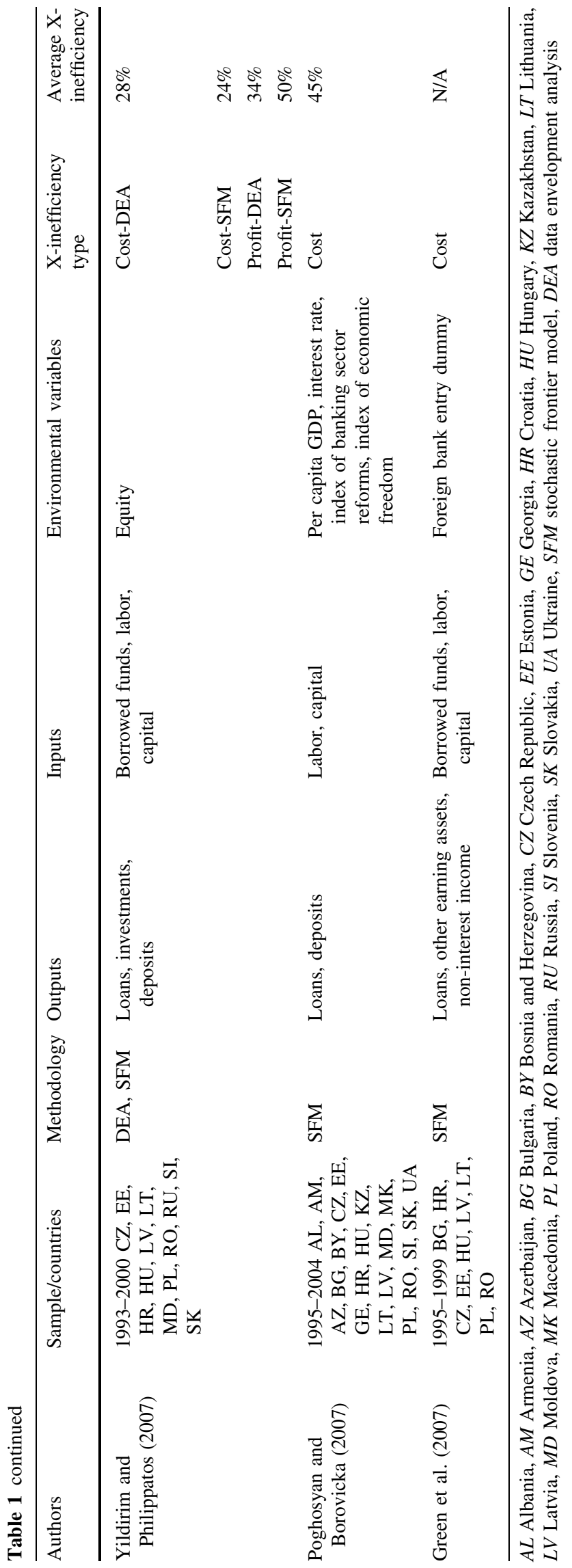

differences might be inappropriately labeled as inefficiency in single-frontier estimations. Consequently, the impact of inefficiency determinants might be misunderstood. Another drawback of the homogenous technological regime assumption is that it imposes restrictions on certain important characteristics of banking technology, such as technical progress and scale economies.

There are several approaches that can accommodate technological differences. One approach is to include country-specific environmental variables that are likely to influence technologies of banks, such as the level of economic development and institutional background, as additional explanatory variables in the frontier (Berger 2007). In fact, most of the cross-country studies reviewed in Table 1 augment the frontier by country-specific variables (Fries and Taci 2005; Bonin et al. 2005; Yildirim and Philippatos 2007; Poghosyan and Borovicka 2007; Green et al. 2007). The main disadvantage of this approach is that the introduction of the environmental variables only affects the intercept of the frontier specification, leaving the slope parameters unaffected (Bos and Schmiedel 2007). Thus, although more flexibility in intercepts may partially alleviate the bias in inefficiency estimates (Valverde et al. 2007), the constancy of the slope parameters will still impose restrictions on technical progress and scale economies of banks. Another drawback of this approach is that technological differences are assumed to be country-specific, which rules out the possibility that banks located within the same country may employ different business models (Koetter and Poghosyan 2009).

An alternative approach to alleviate the impact of technological differences is a priori sample separation. The sample separation can be based, for instance, on the organizational structure of banks (Mester 1993; Altunbas et al. 2001), or their geographical location (Mester 1996; Bos and Schmiedel 2007). The main disadvantage of this approach is that a priori restriction of sample separation is to some extent arbitrary. For instance, Koetter and Poghosyan (2009) show that even banks having similar organizational structure can operate under different technological regimes.

In this study, we account for differences in technological regimes using a latent class stochastic frontier model (LCSFM), which addresses the disadvantages associated with the aforementioned alternative approaches (Orea and Kumbhakar 2004; Greene 2005). ${ }^{3}$ Unlike the first approach, the impact of the environmental factors is not only reflected in the magnitude of the intercepts, but also affects the slope coefficients. Here, the environmental variables enter as latent class determinants rather than as a part of the frontier and thus influence both estimates of the

\footnotetext{
3 To our best knowledge, this is the first application of the LCSFM for studying cost efficiency of banks in FSE.
} 
technological regime of banks and their cost efficiency simultaneously. Unlike the second approach, the latent class method does not require a priori grouping of banks. Instead, it utilizes all information available in the sample and identifies separate technological regimes based on the maximum likelihood principle.

Our results support the conclusion reached by Orea and Kumbhakar (2004) that single-frontier methods result in upward-biased estimates of bank efficiency, since in these models technological differences can be mistakenly attributed to inefficiency. We find that banks in FSE operate under three distinct technological regimes. These technological regimes are shaped by differences across FSE in terms of progress in economic reforms, economic uncertainty, capital regulation, and market structure in the banking sector. We find that progress in economic reforms and low level of risk contribute to bank performance in FSE. In addition, bank efficiency improves in less concentrated banking industries, supporting the structureconduct-performance hypothesis. Technology differences matter also for the relationship between foreign ownership and bank performance widely analyzed in previous work. We find that positive impact of foreign ownership on bank efficiency is present only in less developed FSE with higher degree of risk, while this relationship does not hold for more advanced and stable FSE. Finally, we provide evidence supporting the hypothesis that adoption of EU standards by the new EU member FSE has contributed to the improved bank performance in these countries.

The remainder of the paper is structured as follows. The next section presents the LCSFM and estimation details. A data description is provided in Sect. 3, while the estimation results are discussed in Sect. 4. The last section concludes.

\section{Accounting for heterogeneity of banking technologies: a latent class stochastic frontier model}

In our LCSFM, we assume that the technology is represented by a cost function in the translog form. Following Orea and Kumbhakar (2004), the cost function for class $k$ may be written as:

$\ln C_{i t}=\ln C\left(y_{i t}, w_{i t}, t ; \beta_{k}\right)+u_{i t \mid k}+v_{i t \mid k}$,

where subscripts $i=1, \ldots, N \quad t=1, \ldots, T_{i}$, and $k=$ $1, \ldots, K$, stand for bank, time, and class, respectively; $C_{i t}$ is individual bank total cost; $y_{i t}$ and $w_{i t}$ indicate vectors of outputs and input prices; and $\beta_{k}$ is a class-specific vector of parameters to be estimated. The two-sided random error term $v_{i t k}$ is assumed to be independent of the non-negative cost inefficiency variable $u_{i t k}$ for each class.

To estimate the model using maximum likelihood we assume that the random error term for class $k, v_{i t k}$, follows a normal distribution with zero mean and constant variance, $\sigma^{2}{ }_{v k}$. In addition, one has to impose some structure on the temporal behavior of cost inefficiency for class $k, u_{i t k}$, first and then make a distributional assumption on the random component. This can be done in several ways. For example, if $u_{i t \mid k}$ is assumed to be independently and identically distributed (i.i.d.) across $i$ and $t$ as half normal, ${ }^{4}$ then the likelihood function for bank $i$ belonging to class $k$ at time $t$ can be written (see Greene 2005) as: ${ }^{5}$

$$
\begin{aligned}
\operatorname{LF}_{i t}\left(\theta_{k}\right)= & \frac{\Phi\left(-\varepsilon_{i t \mid k} \frac{\sigma_{u k}}{\sigma_{v k} \sqrt{\sigma_{v k}^{2}+\sigma_{u k}^{2}}}\right)}{\Phi(0)} \\
& \times \frac{1}{\sqrt{\sigma_{v k}^{2}+\sigma_{u k}^{2}}} \phi\left(\frac{\varepsilon_{i t \mid k}}{\sqrt{\sigma_{v k}^{2}+\sigma_{u k}^{2}}}\right),
\end{aligned}
$$

where $\varepsilon_{i t \mid k}=u_{i t k}+v_{i t \mid k}$ is the compounded disturbance term; $\theta_{k}=\left(\beta_{k}, \sigma^{2}{ }_{v k}, \sigma^{2}{ }_{u k}, \eta_{k}\right)$ are parameters describing the technology of banks belonging to class $k$; and $\Phi($.$) and$ $\phi($.$) are standard normal cumulative and density functions,$ respectively. Thus, the overall contribution of bank $i$ to the conditional likelihood can be derived using a product of likelihood functions: $\operatorname{LF}_{i k}\left(\theta_{k}\right)=\prod_{t=1}^{T_{i}} \operatorname{LF}_{i t}\left(\theta_{k}\right)$.

The other extreme, following the panel data models, is to assume that cost inefficiency in class $k$ is product of a time-invariant random bank-specific effect, $u_{i \mid k}$ (usually half-normal), and a non-negative deterministic parametric function of time and other explanatory variables $z$, $u_{i t k}=\lambda_{i t}\left(z_{i t}^{\prime} \eta_{k}\right) u_{i \mid k}$. Since $u_{i t \mid k}$ is not i.i.d. over $t$, the likelihood function for class $k$ has to be defined for bank $i$ covering all time periods. If $\lambda_{i t}\left(z_{i t}^{\prime} \eta_{k}\right)=1$, then this specification collapses to the case when inefficiency is time invariant (see Pitt and Lee 1981; Kumbhakar and Lovell 2000 for the appropriate likelihood function) for a given $k{ }^{6}$

One can also consider a case where the $z$ variables in $\lambda$ are only time-varying (i.e., they are the same for all banks). See Kumbhakar (1990) and Lee and Schmidt (1993) for more on these models, which are summarized in Kumbhakar and Lovell (2000). The likelihood functions for these models can be viewed as the conditional likelihood for class $k$ simply by adding the class subscript $k$.

Here we follow Orea and Kumbhakar (2004) and specify cost inefficiency $u_{i t \mid k}$ as:

$u_{i t \mid k}=\lambda_{i t}\left(z_{i t}^{\prime} \eta_{k}\right) u_{i \mid k}=\mathrm{e}^{\left(z_{i i}^{\prime} \eta_{k}\right)} u_{i \mid k}$,

\footnotetext{
4 The half normal distribution is the normal distribution with mean zero and constant variance truncated at zero from below.

5 Notice that this formulation does not exploit the panel nature of the data.

${ }^{6}$ Note that although these likelihood functions are for the singlefrontier models, they can be used in the latent class models simply by adding the class subscript $k$.
} 
where $u_{i \mid k} \geq 0 ; \eta_{k}=\left(\eta_{1 k}, \ldots, \eta_{H k}\right)^{\prime}$ is a $H \times 1$ vector of parameters and $z_{i t}=\left(z_{1 i t}, \ldots, z_{H i t}\right)^{\prime}$ is a $H \times 1$ vector of determinants of cost inefficiency. The log likelihood function $\ln \operatorname{LF}_{i}\left(\theta_{i k}\right)$ (defined for a bank $i$ for all time periods) is given in Eq. 3 in Orea and Kumbhakar (2004) and is not repeated here. Since the likelihood function is defined for a bank over all time periods, there is no time subscript.

The unconditional likelihood of bank $i$ is obtained as a weighted sum of the $k$-class likelihood functions. The weights are the class membership probabilities reflecting the uncertainty regarding the true membership in the sample. A convenient way to parameterize the class probabilities is to employ a multinomial logit model:

$P_{i k}\left(\delta_{k}\right)=\frac{\mathrm{e}^{\left(\delta_{k}^{\prime} \mathrm{q}_{\mathrm{i}}\right)}}{\sum_{k=1}^{K} \mathrm{e}^{\left(\delta_{k}^{\prime} q_{i}\right)}}$,

where $k=1, \ldots, K$, denote classes; $\delta_{K}=0$ is a parameter normalization for the reference class and $q_{i}$ is a vector of bank-specific and time-invariant class determinants. Using weights $P_{i k}$ from Eq. 4, the unconditional likelihood for bank $i$ can be written as:

$\operatorname{LF}_{i}(\theta, \delta)=\sum_{k=1}^{K} \operatorname{LF}_{i k}\left(\theta_{k}\right) P_{i k}\left(\delta_{k}\right)$,

where $0 \leq P_{i k} \leq 1$ and $\sum_{k=1}^{K} P_{i k}=1$. Combining Eqs. 2 and 4 results in an overall likelihood function involving parameters $\theta$ and $\delta$ :

$\ln \operatorname{LF}(\theta, \delta)=\sum_{i=1}^{N} \ln \operatorname{LF}_{i}(\theta, \delta)=\sum_{i=1}^{N} \ln \left\{\sum_{k=1}^{K} \operatorname{LF}_{i k}\left(\theta_{k}\right) P_{i k} \delta_{k}\right\}$.

Note that to identify the parameters of latent class probabilities, the sample has to be generated from different technological regimes in which the banks are operating. Hence, the number of classes $K$ determined by the means of information criteria should not exceed the number of true regimes in the sample, otherwise the parameters cannot be identified.

Unlike the standard stochastic frontier approach, where the cost frontier is the same for each bank, in the latent class stochastic frontier model we estimate several frontiers (equal to the number of classes). How can the cost inefficiency term be estimated in such a case when there are several benchmarks? One possibility is to assign class membership for an individual bank based on the highest probability and, consequently, use the stochastic frontier estimated for that class as a benchmark against which the cost inefficiency can be computed. However, this approach imposes arbitrary class membership, while the posterior probabilities of class membership are far from certain. An alternative approach, used by Orea and Kumbhakar (2004) and Greene (2005), is based on the weighted average of the cost inefficiency terms:

$\ln \mathrm{EF}_{i}=\sum_{k=1}^{K} P(k \mid i) \ln \mathrm{EF}_{i}(k)$,

where $P(k \mid i)$ is the posterior probability of class- $k$ membership for bank $i$; and $\mathrm{EF}_{i}(k)$ is the bank's cost efficiency using class- $k$ technology as a reference. In this case, technologies from every class are taken into account in estimating the overall cost efficiency.

\section{Data and model specification}

We use bank-level data for various FSE, including both former Soviet republics and Central and Eastern European countries, for the 1993-2004 period. The bank-level data is extracted from financial reports (balance sheets and income statements) available through the BankScope database of Bureau van Dijk.

The data set is complemented by historical ownership information collected from individual bank web-pages and from the EBRD internal database. ${ }^{7}$ The resulting sample covers information on banks from the following twenty countries: Albania (AL), Armenia (AZ), Azerbaijan (AZ), Bulgaria (BG), Bosnia and Herzegovina (BY), Czech Republic (CZ), Estonia (EE), Georgia (GE), Croatia (HR), Hungary (HU), Kazakhstan (KZ), Lithuania (LT), Latvia (LV), Moldova (MD), Poland (PL), Romania (RO), Russia (RU), Slovenia (SI), Slovakia (SK), and Ukraine (UA).

The latent class stochastic frontier model described in the previous section requires three sets of variables determining (1) the stochastic frontier $(C, y, t, w),(2)$ the class membership $(q)$, and (3) the determinants of inefficiency (z). While there is already an established literature describing determinants of cost efficiency in banking (see Berger 2007 for a survey), it is a priori unclear which variables should be used as class membership and bank efficiency determinants. Koetter and Poghosyan (2009) suggest that class membership determinants should reflect environmental characteristics of host countries and should be exogenous to the managerial decisions of banks, whereas bank efficiency determinants should reflect variables under control of bank managers. This approach is intuitively appealing, since it allows differentiating between exogenous factors shaping technological possibilities of banks and managerial decisions of bank administration influencing bank performance relative to its peers operating in the same environment. We adopt this approach

\footnotetext{
7 We thank Anita Taci from the EBRD for kindly sharing her data set.
} 
and provide below a detailed description of three sets of variables used in our analysis.

\subsection{Determinants of cost frontier}

For the stochastic cost frontier, we follow the modified production approach (see Berger and Humphrey 1991) and use two types of bank outputs: total loans $\left(y_{1}\right)$ and total deposits $\left(y_{2}\right)$. The banks produce their services using two inputs, physical capital and labor. Accordingly, the price of the physical capital is measured as a ratio of non-interest expenses to total assets $\left(w_{1}\right)$, while the price of labor is proxied by the ratio of total personnel expenses to total assets $\left(w_{2}\right){ }^{8}$ The dependent variable in the frontier is the total cost of banks $(C)$, which includes both interest and operating expenses.

\subsection{Determinants of class membership}

Following the literature, we assume that technological possibilities of banks are influenced by the following institutional, macroeconomic, regulatory, and market structure characteristics of host countries.

- Economic reforms: During the last two decades, most FSE have implemented various economic policies, such as privatization, liberalization of financial markets, development of infrastructure, legal reforms, that have ultimately influenced demand for bank services. Although all FSE have achieved certain progress in reforming their economies, the pace of reforms has to a great extent differed across FSE (EBRD 2006). Arguably, banks located in FSE which made greater progress in terms of economic reforms and have better institutions are expected to have more opportunities for technical progress and business expansion (Poghosyan and De Haan 2008). We use first principal component of nine indices of economic reforms (referring to smalland large-scale privatization, enterprize reforms, price liberalization, foreign exchange and trade liberalization, competition policy, banking and non-banking sector reforms, reforms in infrastructure) developed by EBRD to measure relative progress of FSE in terms of economic reforms $(E B R D)$.

- Capitalization: The scope of banking activities is directly affected by minimum capital requirements imposed on banks by supervisory authorities. Intuitively, banks operating in countries with higher capital requirements have limited scope for leverage relative to banks operating in countries with lower capital

\footnotetext{
8 In the absence of a reliable information on the number of bank employees, it has become customary in the literature to proxy labor costs by deflating labor expenses over total assets (see, for instance, Fries and Taci 2005; Rossi et al. 2004).
}

requirements. Survey of banking regulation by Barth et al. (2001) suggests that FSE are quite heterogeneous in terms of capital requirements, which range between 8 and $12 \%$. We use aggregate bank capitalization at the country level $(C A P)$ to proxy the impact of capital regulation on banking technology.

- Market structure: Level of concentration in the banking sector may have a multifold impact on banking technology. Two competing theories can be distinguished here. According to the structure-conductperformance hypothesis (see Berger et al. 1999 for a survey), more concentrated banking industries encourage monopolistic power, relax competition across banks and have detrimental impact on competitiveness, efficiency, and technological progress. On the contrary, efficiency market hypothesis (Demsetz 1973) suggests that higher concentration may emerge as a result of survival of most innovative and efficient banks. We use Herfindahl index (in terms of bank assets) as a proxy for market concentration $(H E R F)$ to analyze which of these two competitive views holds for our sample.

- Economic development and savings: Other relevant factors influencing banking technology are the level of economic development in the country and saving propensity. It is natural to expect that banks located in more developed economies and countries characterized by high saving rates would experience higher demand for their services and can benefit more from scale economy effects compared to banks located in less developed and low saving economies. Empirical evidence suggests that deeper financial markets improve possibilities for business expansion and reduce fixed costs of financial intermediation (Beck and de la Torre 2007). We use per capital GDP $(G D P P C)$ and ratio of gross domestic savings to GDP $(S A V)$ as measures of economic development and saving propensity in the country, respectively.

- Inflation and credit risks: Finally, banking technology can be sensitive to the level of risks in the economy. Banks located in riskier countries incur larger costs associated with risk management and evaluation of credit information (Fries and Taci 2005). In addition, greater economic uncertainty may result in higher interest rate margins and decrease the scope for financial intermediation in the country (Maudos and Fernandez de Guevara 2004). We use the ratio of loan loss provisions to total loans at the country level $(L L P)$ and inflation $(I N F L)$ as measures of credit risk and economic uncertainty.

\subsection{Determinants of bank efficiency}

We assume that bank managers can influence bank efficiency via two broad channels. The first channel is the 
governance structure proxied by the foreign ownership of banks. There is a large literature analyzing the relationship between foreign ownership and cost efficiency of banks in FSE. Some empirical studies find positive effect of foreign ownership on bank efficiency (Bonin et al. 2005; Fries and Taci 2005; Poghosyan and Poghosyan 2009). Other studies suggest that this relationship may be driven by selection bias, since foreign banks tend to target more efficient banks for acquisition (Poghosyan and Borovicka 2007). We use foreign ownership dummy variable (FOREIGN) that takes the value of one if more than $50 \%$ of bank capital is owned by foreigners to analyze the impact of foreign ownership on cost efficiency conditional on the bank's class membership.

The second channel of transmission are spillover effects from recent financial liberalization and transfer of knowhow from abroad, which might have influenced abilities of bank managers over time (Rossi et al. 2004). Following Battese and Coelli (1992), we use time trend (TIME) to proxy this channel and analyze regime-specific developments of bank efficiency over time.

Descriptive statistics of variables employed in our estimations are displayed in Table 2. The summary statistics across different countries shows that there is a great deal of variation in terms of total costs, outputs, and input prices. In most cases, the new EU member countries are characterized by relatively higher costs accompanied by larger outputs and input prices. Similarly, FSE are described by heterogenous institutional, macroeconomic, regulatory, and market structure characteristics, which may have implications for technological possibilities of banks. This is the question we investigate in the next step.

The final specification of our latent class cost frontier model takes the following form:

$$
\begin{aligned}
\ln \frac{C_{i t}}{w_{i t, 1}}= & \alpha_{k}+\sum_{s=2}^{S} \beta_{s k} \ln \frac{w_{i t, s}}{w_{i t, 1}}+\sum_{l=1}^{L} \gamma_{l k} \ln y_{i t, l} \\
& +\frac{1}{2} \sum_{s=2}^{S} \sum_{l=2}^{S} \delta_{s l k} \ln \frac{w_{i t, s}}{w_{i t k, 1}} \ln \frac{w_{i t, l}}{w_{i t, 1}} \\
& +\frac{1}{2} \sum_{s=1}^{L} \sum_{l=1}^{L} \psi_{s l k} \ln y_{i t, s} \ln y_{i t, l} \\
& +\sum_{s=2}^{S} \sum_{l=1}^{L} \theta_{s l k} \ln \frac{w_{i t, s}}{w_{i t, 1}} \ln y_{i t, l} \\
& +\rho_{1 k} t+\frac{1}{2} \rho_{2 k} t^{2}+\sum_{s=2}^{S} \rho_{s k}^{w} t \ln \frac{w_{i t, s}}{w_{i t, 1}} \\
& +\sum_{l=1}^{L} \rho_{l k}^{y} t \ln y_{i t, l}+v_{i t \mid k}+u_{i t \mid k},
\end{aligned}
$$

where index $k=1, \ldots, K$, expresses class membership.

Linear homogeneity (in input prices) restrictions are imposed by expressing all price and cost variables as a ratio with respect to one of the input prices (capital costs). Inefficiency is modeled as a function of its determinants:

$u_{i t \mid k}=\mathrm{e}^{\left(\eta_{1 k} \text { FOREIGN }+\eta_{2 \mathrm{k}} \text { TIME }\right)} u_{i \mid k}$,

where FOREIGN is the dummy variable for foreign owned banks and TIME is the time trend.

The latent class probabilities are specified as:

$$
\begin{aligned}
& P_{i k}\left(\delta_{k}\right) \\
& =\frac{\mathrm{e}^{\left(\delta_{0 \mathrm{k}}+\delta_{1 \mathrm{k}} \mathrm{EBRD}+\delta_{2 \mathrm{k}} \mathrm{CAP}+\delta_{3 \mathrm{k}} \mathrm{HERF}+\delta_{4 \mathrm{k}} \mathrm{SAV}+\delta_{5 \mathrm{k}} \mathrm{GDPPC}+\delta_{6 \mathrm{k}} \mathrm{INFL}+\delta_{7 \mathrm{k}} \mathrm{LLP}\right)}}{\sum_{k=1}^{K} \mathrm{e}^{\left(\delta_{0 k}+\delta_{1 \mathrm{k}} \mathrm{EBRD}+\delta_{2 \mathrm{k}} \mathrm{CAP}+\delta_{3 \mathrm{k}} \mathrm{HERF}+\delta_{4 \mathrm{k}} \mathrm{SAV}+\delta_{5 \mathrm{k}} \mathrm{GDPPC}+\delta_{6 \mathrm{k}} \mathrm{INFL}+\delta_{7 \mathrm{k}} \mathrm{LLP}\right)},},
\end{aligned}
$$

where $E B R D$ is the first principal component of nine EBRD indices of economic reforms, $C A P$ is the ratio of equity to total assets in the banking system, HERF is the Herfindahl index (in terms of total assets), $S A V$ is the ratio of gross domestic savings to GDP, GDPPC is the per capital GDP (in US dollars), INFL is the CPI inflation, and LLP is the ratio of loan loss provisions to total loans in the banking system.

\section{Estimation results}

\subsection{Selection of the number of classes}

In estimating Eqs. 8, 9, and 10 one needs to find the appropriate number of classes $K$. A customary way of selecting the number of classes is to use the information criteria. We have computed BIC (Schwartz's criterion) statistic for up to three classes. ${ }^{9}$ The statistic increases with the number of classes, which suggests that the preferred model is the one with three latent classes (see Table 3). ${ }^{10}$

To cross-check sensitivity of the class size selection on inefficiency, we estimate the model for one, two, and three classes and compare the average efficiency scores for each of these models. As can be observed from Table 4, the average efficiency monotonically increases with the number of classes. This relationship suggests that the countryspecific heterogeneity in banking technologies, if not taken into account, would lead to downward-biased efficiency score estimates.

The high posterior class probabilities ( $91.6 \%$ on average) reported in Table 3 suggest that the country-specific variables chosen as class determinants in our estimations provide a precise group classification. Therefore, classification

\footnotetext{
9 The BIC statistic can be written as: $\operatorname{BIC}(K)=2 \ln \operatorname{LF}(K)-$ $\Pi(K) \ln \left(\sum_{i=1}^{N} T_{i}\right)$, where $K$ is the number of latent classes, $\Pi(K)$ is the number of parameters to estimate for specification with $K$ latent classes and $T_{i}$ is the number of observations for bank $i$. The best model is the one with the highest BIC statistic.

${ }^{10}$ Models with more than three latent classes are overspecified and could not be estimated using the maximum likelihood methodology.
} 


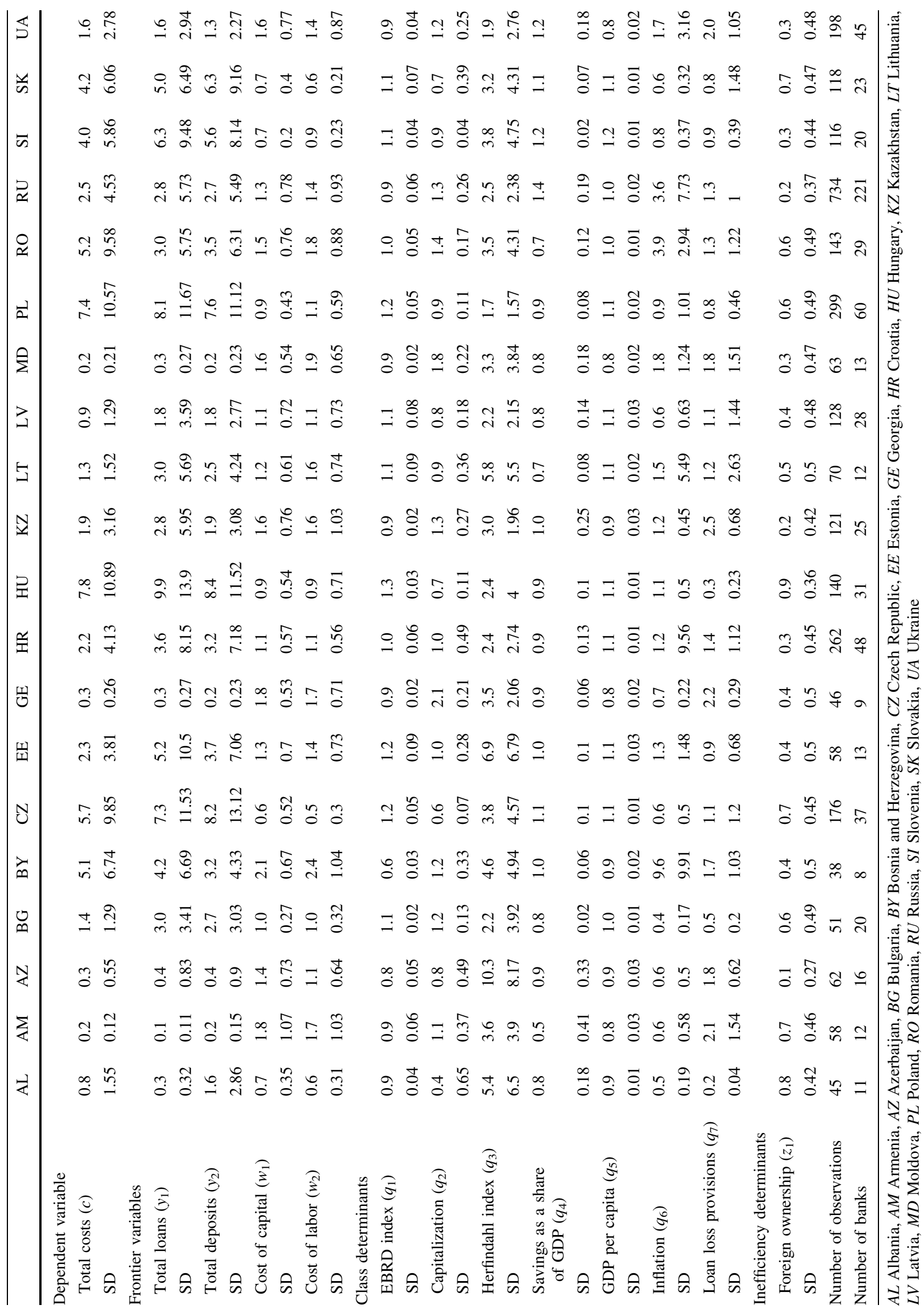


Table 3 Selection of the number of classes

\begin{tabular}{lllll}
\hline $\begin{array}{l}\text { Number } \\
\text { of classes }\end{array}$ & $\begin{array}{l}\text { Number of } \\
\text { parameters }\end{array}$ & $\begin{array}{l}\text { Log- } \\
\text { likelihood }\end{array}$ & BIC & $\begin{array}{l}\text { Posterior class } \\
\text { probability }\end{array}$ \\
\hline 1 & 28 & -796.1 & 1648.1 & 0.830 \\
2 & 56 & -372.3 & 856.6 & 0.810 \\
3 & 84 & -223.7 & 615.5 & 0.916 \\
\hline
\end{tabular}

Notes: the table features SFM estimations for 1,2, and 3 latent classes using 2,926 observations for the period 1993-2004. The BIC statistic is calculated as: $\operatorname{BIC}(K)=2 \ln \mathrm{LF}(K)-\Pi(K) \ln \left(\sum_{i=1}^{N} T_{i}\right)$. where $K$ is the number of latent classes, $\Pi(K)$ is the number of parameters to estimate for specification with $K$ latent classes and $T_{i}$ is the number of observations for bank $i$ (the best model is the one with the highest BIC statistic). The posterior class probability reflects the degree of precision with which banks were classified to classes (higher probability implies higher precision)

Table 4 Average cost efficiency scores for LCSFM with different number of classes

\begin{tabular}{|c|c|c|c|}
\hline \multirow[t]{2}{*}{ Year } & \multicolumn{3}{|l|}{ SFM with } \\
\hline & 1 Latent class & 2 Latent classes & 3 Latent clas \\
\hline 1993 & 0.6272 & 0.7204 & 0.6674 \\
\hline 1994 & 0.5946 & 0.6842 & 0.6093 \\
\hline 1995 & 0.6291 & 0.6905 & 0.6539 \\
\hline 1996 & 0.6353 & 0.6955 & 0.6742 \\
\hline 1997 & 0.6332 & 0.6874 & 0.6641 \\
\hline 1998 & 0.6373 & 0.6758 & 0.6673 \\
\hline 1999 & 0.6474 & 0.6800 & 0.6864 \\
\hline 2000 & 0.6662 & 0.6915 & 0.7089 \\
\hline 2001 & 0.6885 & 0.6975 & 0.7180 \\
\hline 2002 & 0.6987 & 0.6998 & 0.7251 \\
\hline 2003 & 0.7091 & 0.7038 & 0.7342 \\
\hline 2004 & 0.7167 & 0.7044 & 0.7347 \\
\hline Total & 0.6785 & 0.6948 & 0.7079 \\
\hline
\end{tabular}

Notes: the table features average cost efficiency scores obtained for SFM with 1,2, and 3 latent classes using 2,926 observations for the period 1993-2004

of banks into three groups according to their maximum probabilities can be performed with high level of confidence.

\subsection{Parameter estimates and economic interpretation of heterogenous technologies}

Estimates of class-specific parameters are displayed in Table 5. In most cases, the parameters representing the efficiency frontiers are significant at the conventional confidence levels. Distribution of banks across classes is quite even $(35,40$, and $25 \%$ for first, second, and third classes, respectively). Analysis of class determinants suggests that banks classified in the first group are located in countries with greater progress in terms of economic reforms, stricter capital requirements, lower degree of concentration, less economic uncertainty, and lower degree of credit risk relative to the third group. Given these characteristics, we label this technology regime as "Stable and Competitive". Similar to the first group, banks classified in the second group are located in countries with greater progress in terms of economic reforms and lower degree of credit risk relative to the third group. However, these banks are also located in countries with lower degree of savings relative to the third group. Therefore, we label the second technology regime as "Stable and Limited". By default, the third technology regime can be described as "Uncertain and Striving", since it is characterized by banks located in economic environments with lesser progress of economic reforms, more leverage, higher concentration, and greater uncertainty.

What are the implications of differences in economic environments and technology regimes for bank performance? Distribution of average efficiency scores across classes reported in Table 6 suggests that banks located in the first and second classes exhibit greater cost efficiency (73\%) than banks located in the third class (61\%), implying that stable economic environment has positive contribution to cost efficiency in banking. This outcome supports findings of Mester (1996), who shows that efficiency differences across banks can be related to differences in risk exposure and advocates accounting for risk when analyzing bank efficiency. Determinants of bank efficiency reported in the middle panel of Table 5 suggest different response of inefficiency to managerial determinants across groups. For instance, in line with findings by Bonin et al. (2005) and Fries and Taci (2005), foreign ownership improves bank efficiency in the "Uncertain and Striving" regime. However, foreign ownership has detrimental impact for bank efficiency in "Stable and Competitive" regime, which is in line with findings of Poghosyan and Borovicka (2007). This result provides support for the hypothesis that decision of foreign banks to enter FSE depends on the level of development and quality of institutions in host countries (Poghosyan and De Haan 2008). In addition, this result shows that foreign banks have larger scope to improve efficiency of target banks located in less developed countries characterized by higher degree of uncertainty relative to that of banks located in more developed and stable FSE.

Finally, our results provide support for the structureconduct-performance hypothesis, since relatively more efficient "Stable and Competitive" regime has lower level of concentration compared to the less efficient "Uncertain and Striving" regime. This finding can be an outcome of the quiet life notion advocated by Berger and Hannan (1998), according to which banks possessing greater market power are reluctant to improve their efficiency.

We also estimate two auxiliary measures based on the estimated frontier parameters, viz., technical change (TC) 
Table 5 LCM estimation results

\begin{tabular}{|c|c|c|c|c|c|c|}
\hline & \multicolumn{2}{|l|}{ Class 1} & \multicolumn{2}{|l|}{ Class 2} & \multicolumn{2}{|l|}{ Class 3} \\
\hline & Coeff. & $t$-Ratio & Coeff. & $t$-Ratio & Coeff. & $t$-Ratio \\
\hline Intercept & -0.0513 & -0.8390 & -1.1184 & -7.6330 & -0.1928 & -0.8630 \\
\hline Loans & -0.3572 & -7.2100 & 0.2225 & 3.9720 & 0.2491 & 2.2900 \\
\hline Deposits & 1.4324 & 28.6640 & 0.7984 & 15.2000 & 0.7738 & 7.7080 \\
\hline Price of labor/price of capital & 0.5203 & 10.1490 & 0.4806 & 7.7050 & 0.6438 & 4.9490 \\
\hline Trend & -0.0216 & -1.3100 & 0.1033 & 3.6070 & 0.0351 & 0.6830 \\
\hline$(\text { Loans })^{2}$ & 0.1233 & 6.1070 & 0.2183 & 8.8300 & 0.0221 & 0.5930 \\
\hline (Loans) $\times$ (deposits $)$ & -0.1410 & -9.1670 & -0.2379 & -9.7750 & -0.0923 & -2.8500 \\
\hline (Loans) $\times$ (price of labor/price of capital) & 0.2691 & 9.7810 & -0.0568 & -2.0390 & -0.0367 & -0.7070 \\
\hline$($ Loans $) \times$ trend & 0.0637 & 11.8770 & 0.0110 & 1.9460 & -0.0188 & -1.5520 \\
\hline$(\text { Deposits })^{2}$ & 0.1937 & 13.1140 & 0.2819 & 11.4430 & 0.2243 & 5.7050 \\
\hline$($ Deposits $) \times($ price of labor/price of capital $)$ & -0.3178 & -11.3920 & 0.0753 & 2.7850 & -0.0079 & -0.1360 \\
\hline$($ Deposits $) \times$ trend & -0.0678 & -12.5390 & -0.0150 & -2.8640 & 0.0131 & 1.1220 \\
\hline$\left(\right.$ Price of labor/price of capital) ${ }^{2}$ & 0.3338 & 8.9430 & 0.2928 & 10.6160 & -0.0347 & -0.5110 \\
\hline$($ Price of labor/price of capital) $\times$ trend & 0.0228 & 3.6720 & 0.0134 & 1.9510 & 0.0061 & 0.4030 \\
\hline$(\text { Trend })^{2}$ & -0.0066 & -2.9060 & -0.0094 & -3.2620 & -0.0125 & -1.9840 \\
\hline Sigma & 0.7886 & 3.3421 & 0.9556 & 2.2562 & 0.8360 & 3.3245 \\
\hline Lambda & 0.1093 & 0.4346 & 0.3839 & 0.0034 & 0.8447 & 0.7644 \\
\hline \multicolumn{7}{|l|}{ Inefficiency determinants } \\
\hline Intercept & -0.7552 & 0.0000 & 1.1211 & 0.0000 & -0.1015 & 0.0000 \\
\hline FOREIGN & 0.0005 & 3.1740 & 0.0000 & 0.3910 & -0.0004 & -5.3620 \\
\hline TIME & 0.1452 & 16.4600 & -0.1980 & -21.8380 & -0.0155 & -1.0650 \\
\hline \multicolumn{7}{|l|}{ Class determinants } \\
\hline Intercept & 3.4289 & 1.0260 & 9.9720 & 3.1290 & - & - \\
\hline EBRD & 5.7876 & 2.2480 & 5.7299 & 2.1420 & - & - \\
\hline CAP & 1.2642 & 1.6600 & -0.5225 & -0.7680 & - & - \\
\hline HERF & -0.1545 & -2.1320 & 0.0562 & 1.1260 & - & - \\
\hline SAV & -1.4197 & -1.5330 & -3.3525 & -4.3150 & - & - \\
\hline GDPPC & 5.3145 & 1.5010 & 1.2639 & 0.3150 & - & - \\
\hline INFL & -0.5010 & -2.4250 & -0.1878 & -1.0960 & - & - \\
\hline LLP & -0.7195 & -2.5730 & -0.5405 & -2.4720 & - & - \\
\hline Prior class probabilities at data means & 0.35 & & 0.40 & & 0.25 & \\
\hline
\end{tabular}

Notes: 2,926 observations for the 1993-2004 period. Dependent variable is $\ln \frac{C_{i t}}{w_{i t 1}}$. FOREIGN, dummy variable for foreign owned banks; TIME, time trend; EBRD, the first principal component of nine EBRD indices of economic reforms; CAP, the ratio of equity to total assets in the banking system; HERF, the Herfindahl index (in terms of total assets); SAV, the ratio of gross domestic savings to GDP; GDPPC, the per capital GDP (in US dollars); INFL, the CPI inflation; LLP, the ratio of loan loss provisions to total loans in the banking system

and economies of scale (SCE) - to provide an economic interpretation of the results. Following the literature (see e.g., Orea and Kumbhakar 2004), we measure technical progress as the derivative of total costs with respect to time $(\mathrm{TC}=\partial \ln C / \partial t)$ calculated at sample means. $T C$ captures the effect of change in banking production technology following innovations not explained by outputs and income prices. A negative sign for this indicator implies technological progress (decrease in bank costs over time). We find that only "Stable and Competitive" regime exhibits significant technological progress $(\mathrm{TP}=-\mathrm{TC}$ evaluated at the mean is $13.6 \%$ with a $t$-value of 5.75 ), whereas technological progress is insignificant in second and third regimes. This finding provides empirical evidence for the notion that more competitive banking industries exhibit greater technological progress (Kumbhakar and Sarkar 2003).

The second measure is economies of scale estimated as one minus the sum of elasticities of total costs with respect to outputs ( $\left.\mathrm{SCE}=1-\sum_{k} \partial \ln C / \partial \ln y_{k}\right)$. For constant returns to scale technology, this measure should be equal to zero. A negative measure implies that banks are operating 
Table 6 Comparison of cost efficiency scores

\begin{tabular}{lllll}
\hline Year & Class 1 & Class 2 & Class 3 & Average \\
\hline 1993 & 0.8834 & 0.3124 & 0.7159 & 0.6373 \\
1994 & 0.8309 & 0.3546 & 0.6713 & 0.6189 \\
1995 & 0.8372 & 0.4555 & 0.6600 & 0.6509 \\
1996 & 0.8355 & 0.5168 & 0.6465 & 0.6663 \\
1997 & 0.8038 & 0.5886 & 0.5858 & 0.6594 \\
1998 & 0.7767 & 0.6244 & 0.5789 & 0.6600 \\
1999 & 0.7725 & 0.6505 & 0.5991 & 0.6740 \\
2000 & 0.7659 & 0.7047 & 0.6037 & 0.6914 \\
2001 & 0.7383 & 0.7488 & 0.6156 & 0.7009 \\
2002 & 0.7142 & 0.7880 & 0.6126 & 0.7049 \\
2003 & 0.6879 & 0.8214 & 0.6253 & 0.7115 \\
2004 & 0.6466 & 0.8506 & 0.6284 & 0.7085 \\
Average & 0.7328 & 0.7329 & 0.6138 & 0.6932 \\
\hline
\end{tabular}

Notes: the table features average cost efficiency scores obtained for the SFM with 3 latent classes using 2,926 observations for the period 1993-2004. The classification of banks by classes is performed using the maximum probability principle (e.g., the bank is assigned to class 1 if the probability of being in class 1 is higher than probabilities obtained for classes 2 and 3 )

at the decreasing returns to scale part of the cost function. We find that banks in the "Stable and Competitive" regime exhibit decreasing returns to scale technology (SCE at the mean is $7.5 \%$ with a $t$-value of 4.6 ), implying that more developed and stable FSE are characterized by saturated banking markets, in which scopes for scale economies are limited. On the other hand, the "Stable and Limited" regime exhibits increasing returns to scale (SCE at the mean is $14.6 \%$ with a $t$-value of 96.8 ), implying potential for expansion in some stable FSE. SCE is insignificant for the third regime, suggesting constant returns to scale for this group of banks.

\subsection{Does EU membership matter?}

The next step in our investigation is to search for a pattern between class-membership of banks and their country of origin, with particular emphasis on the EU membership. The aim of this exercise is to test whether gradual adoption of EU standards by new EU member FSE have influenced technology regimes of banks located in these countries (EBRD 2006). We assign observations for each of the countries in our sample to three classes based on their maximum probabilities (see Table 7). As mentioned before, the possible imprecision in doing this allocation is low given very large posterior class membership probabilities (about $90 \%$ on average).

The results suggest that six out of the eight new EU member countries are assigned to the best performing

Table 7 Assigning class membership

\begin{tabular}{|c|c|c|c|c|c|c|c|c|c|}
\hline & \multicolumn{4}{|c|}{ Number of obs. } & \multicolumn{4}{|l|}{ Frequency } & \multirow[t]{2}{*}{ EU member } \\
\hline & Class 1 & Class 2 & Class 3 & Total & Class $1(\%)$ & Class $2(\%)$ & Class $3(\%)$ & Class membership & \\
\hline $\mathrm{AL}$ & 6 & 30 & 9 & 45 & 13 & 67 & 20 & 2 & \\
\hline $\mathrm{AM}$ & 22 & 36 & 58 & 116 & 19 & 31 & 50 & 3 & \\
\hline $\mathrm{AZ}$ & 1 & 55 & 6 & 62 & 2 & 89 & 10 & 2 & \\
\hline BG & 20 & 31 & 51 & 102 & 20 & 30 & 50 & 3 & YES \\
\hline BY & 38 & 38 & & 76 & 50 & 50 & & 2 & \\
\hline $\mathrm{CZ}$ & 63 & 44 & 69 & 176 & 36 & 25 & 39 & 3 & YES \\
\hline $\mathrm{EE}$ & 10 & 45 & 3 & 58 & 17 & 78 & 5 & 2 & YES \\
\hline GE & 19 & 27 & 46 & 92 & 21 & 29 & 50 & 3 & \\
\hline HR & 84 & 162 & 16 & 262 & 32 & 62 & 6 & 2 & \\
\hline $\mathrm{HU}$ & 50 & 52 & 38 & 140 & 36 & 37 & 27 & 2 & YES \\
\hline $\mathrm{KZ}$ & 44 & 71 & 6 & 121 & 36 & 59 & 5 & 2 & \\
\hline LT & 4 & 57 & 9 & 70 & 6 & 81 & 13 & 2 & YES \\
\hline LV & 19 & 86 & 23 & 128 & 15 & 67 & 18 & 2 & YES \\
\hline MD & 41 & 22 & 63 & 126 & 33 & 17 & 50 & 3 & \\
\hline PL & 199 & 46 & 54 & 299 & 67 & 15 & 18 & 1 & YES \\
\hline RO & 19 & 82 & 42 & 143 & 13 & 57 & 29 & 2 & YES \\
\hline RU & 341 & 149 & 244 & 734 & 46 & 20 & 33 & 1 & \\
\hline SI & 90 & 19 & 7 & 116 & 78 & 16 & 6 & 1 & YES \\
\hline SK & 44 & 42 & 32 & 118 & 37 & 36 & 27 & 1 & YES \\
\hline UA & 75 & 69 & 54 & 198 & 38 & 35 & 27 & 1 & \\
\hline
\end{tabular}

$A L$ Albania, $A M$ Armenia, $A Z$ Azerbaijan, $B G$ Bulgaria, $B Y$ Bosnia and Herzegovina, $C Z$ Czech Republic, $E E$ Estonia, $G E$ Georgia, $H R$ Croatia, $H U$ Hungary, KZ Kazakhstan, LT Lithuania, LV Latvia, MD Moldova, PL Poland, RO Romania, $R U$ Russia, SI Slovenia, SK Slovakia, UA Ukraine 
"Stable and Competitive" and "Stable and Limited" classes, and the rest is classified to the worst performing "Uncertain and Striving" class. Thus, our findings provide empirical support to the hypothesis that EU membership has served as an anchor for FSE to improve their institutions and achieve better economic performance and stability, which in turn has resulted in better performing technological regimes in banking.

On the contrary, banks from many former Soviet republics with a low level of economic development are assigned to the worst performing "Uncertain and Striving" class. These countries are characterized by less efficient banks which do not exhibit technological progress and scale economies. Thus, our results provide support for the hypothesis that EU membership has helped FSE banks to improve their performance.

\section{Conclusions}

This study provides evidence on the heterogeneity of technology regimes in FSE banking. Using a latent class stochastic frontier modeling approach, we show that environmental variables exogenous to bank managers, such as progress in economic reforms, economic uncertainty, prudential regulation, and market structure, have important influence on the technology employed by banks.

Several important implications can be drawn from our analysis. First, in line with Orea and Kumbhakar (2004), we show that the single-frontier methods employed in previous studies result in an upward-bias of inefficiency estimates, since technological differences are mistakenly attributed to inefficiency. Second, we find that more stable economic environment contributes to greater efficiency, which supports earlier evidence by Mester (1996) that efficiency differences across banks can be related to the degree of risk undertaken. Third, we find that the impact of foreign ownership on bank efficiency is conditional on the technology class dictated by the economic environment of host countries. In particular, performance of foreign banks in FSE with high level of uncertainty outperforms that of domestic banks, which provides support for findings by Bonin et al. (2005) and Fries and Taci (2005). However, the scope for efficiency improvement due to foreign ownership is limited in more developed and stable FSE. Fourth, we find support for the structure-conduct-performance hypothesis, according to which more concentrated banking industries have lower performance. Finally, our results support the hypothesis advocated by FSE policymakers that EU membership would improve technological possibilities of banks and would contribute to their performance.

Overall, our results show the importance of accounting for differences in technology types/regimes when analyzing cost efficiency in FSE banking. Given the important role that banking sector plays for financial intermediation in FSE, further work needs to be conducted to analyze implications of technology differences in banking for the economic development and growth in FSE.

Open Access This article is distributed under the terms of the Creative Commons Attribution Noncommercial License which permits any noncommercial use, distribution, and reproduction in any medium, provided the original author(s) and source are credited.

\section{References}

Altunbas Y, Evans L, Molyneux P (2001) Bank ownership and efficiency. J Money Credit Bank 33(4):926-954

Barth J, Caprio G, Levine R (2001) Banking systems around the globe: do regulations and ownership affect performance and stability? In: Mishkin FS (ed) Prudential supervision: what works and what doesn't. Univ of Chicago Press, Chicago, pp 31-88

Battese G, Coelli T (1992) Frontier production function, technical efficiency and panel data: with application to paddy farmers in India. J Product Anal 3:153-169

Beck T, de la Torre A (2007) The basic analytics of access to financial services. Financ Mark Inst Instrum 16(2):79-117

Berger A (2007) International comparisons of banking efficiency. Financ Mark Inst Instrum 16(3):119-144

Berger A, Demsetz R, Strahan P (1999) The consolidation of the financial services industry: cause, consequences, and implications for the future. J Bank Financ 23:135-194

Berger A, Hannan T (1998) The efficiency cost of market power in the banking industry: a test of the "quiet life" and related hypotheses. Rev Econ Stat 80:454-465

Berger A, Humphrey D (1991) The dominance of Inefficiencies over scale and product mix economies in banking. J Monet Econ 28:117-148

Berger A, Mester L (1997) Inside the black box: what explains differences in the efficiency of financial institutions? J Bank Financ 21:895-947

Bonin J, Hasan I, Wachtel P (2005) Bank privatization and performance: evidence from transition countries. J Bank Financ 29:31-53

Bos J, Schmiedel H (2007) Is there a single frontier in a single European banking market? J Bank Financ 31:2081-2102

Coelli T, Rao P, O'Donnell C, Battese G (2005) An introduction to efficiency and productivity analysis, 2nd edn. Springer, New York

Demsetz H (1973) Industry structure, market rivalry, and public policy. J Law Econ 16(1):1-9

EBRD (2006) Transition report. European Bank of Reconstruction and Development, London

Fries S, Taci A (2005) Cost efficiency of banks in transition: evidence from 289 banks in 15 post-communist countries. J Bank Financ 29:55-81

Green C, Murinde V, Nikolov I (2007) The efficiency of foreign and domestic banks in Central and Eastern Europe: evidence on economies of scale and scope. J Emerg Mark Financ 3(2): $175-205$

Greene W (2005) Reconsidering heterogeneity in panel data estimators of the stochastic frontier model. J Econom 126;269-303

Hughes J, Mester L (2008) Efficiency in banking: theory, practice, and evidence. Wharton school working paper no. 08-1

Koetter M, Poghosyan T (2009) The identification of technology regimes in banking: implications for the market power-fragility nexus. J Bank Financ 33:1413-1422 
Kumbhakar S (1990) Production frontiers and panel data and time varying technical efficiency. J Econom 46:201-211

Kumbhakar S, Lovell K (2000) Stochastic frontier analysis. Cambridge University Press, Cambridge

Kumbhakar S, Sarkar S (2003) Deregulation, ownership, and productivity growth in the banking industry: evidence from India. J Money Credit Bank 35(3):403-424

Lee Y, Schmidt P (1993) A production frontier model with flexible temporal variation in technical inefficiency. In: Fried H, Lovell $\mathrm{K}$ (eds) The measurement of productive efficiency: techniques and applications. Oxford University Press, New York

Maudos J, Fernandezde Guevara J (2004) Factors explaining the interest margin in the banking sectors of the European Union. J Bank Financ 28:2259-2281

Mester L (1993) Efficiency in the savings and loan industry. J Bank Financ 17(2/3):267-286

Mester L (1996) A study of bank efficiency taking into account riskpreferences. J Bank Financ 20:1025-1045

Orea L, Kumbhakar S (2004) Efficiency measurement using a latent class stochastic frontier model. Empir Econ 29:169-183

Pitt M, Lee L (1981) The measurement and sources of technical inefficiency in the Indonesian weaving industry. J Dev Econ 9:43-64
Poghosyan T, Borovicka J (2007) Banking efficiency in emerging economies: the impact of ownership endogeneity and EU accession. CERGE-EI discussion paper no. 189

Poghosyan T, De Haan J (2008) Determinants of cross-border bank acquisitions in transition economies: a latent class analysis. CESifo working paper no. 2372

Poghosyan T, Poghosyan A (2009) Foreign bank entry, bank efficiency and market power in Central and Eastern European countries. Econ Transit (forthcoming)

Rossi S, Schwaiger M, Winkler G (2004) Banking efficiency in Central and Eastern Europe. Financ Stab Rep OeNB 8:77-91

Sealey C, Lindley J (1977) Inputs, outputs, and a theory of production and cost at depository financial institutions. J Financ 32:1251-1266

Valverde S, Humphrey D, Lopez del Paso R (2007) Opening the black box: finding the source of cost inefficiency. J Product Anal 27:209-220

Yildirim H, Philippatos G (2007) Efficiency of banks: recent evidence from the transition economies of Europe, 1993-2000. Eur J Financ 31:123-143 